African Research Review

An International Multidisciplinary Journal, Ethiopia

Vol. 10(1), Serial No.40, January, 2016: 178-192

ISSN 1994-9057 (Print)

ISSN 2070--0083 (Online)

Doi: http://dx.doi.org/10.4314/afrrev.v10i1.14

\title{
Assets Impairment Testing: An Analysis of IAS 36
}

\author{
Oghoghomeh, Tennyson, Ph.D. \\ Department of Accounting and Finance \\ Delta State University Asaba
}

\&
Akani, Fynface N., Ph.D.
Department of Accounting
University of Port Harcourt

\begin{abstract}
The primary objective of accounting is to provide information about the economic resources of an enterprise, the claims to those resources, and the effects of transactions, events, and circumstances that change the resources and claims. It is therefore considered important to inform users of financial statement of any asset or cash generating unit that lose its capacity to recover its cost. This is necessary so as to provide accounting information users with relevant information about the change in value of the firm's resources. An asset that loses its capacity to recover cost is said to be impaired and accounting for asset impairment is faced with a few challenges. It can be difficult to determine which measure of value should be used when assessing impairment. Options include current cost (replacement cost), current market value (selling price), net realizable value (selling price minus disposal costs), or the sum of the future net cash flows from the income-generating unit. More so, there is little guidance by IAS 36 on accounting for asset impairments: when to recognize impairments, how impairments should be measured and how impairment should be disclosed. Since assets impairment can distort the usefulness of accounting information
\end{abstract}


for decision making, adequate attention should be made to ensure that the judgment and estimates made by managers are verified by auditing the estimates.

Key words: Asset impairment, testing, IAS 36.

\section{Introduction}

The objective of impairment recognition is to improve the usefulness of financial statement information by reporting losses in a timely manner. Information on asset impairments should be relevant in evaluating the operating capacity and risks of a firm, and should assist investors in better approximating economic values of assets and in estimating the returns on their investment (Amiraslani, Latridis \& Pope, 2013).

Under IFRS, the relevant requirements governing impairment reporting for non-current non-financial assets are set out mainly in IAS 36 Impairment of Assets together with certain asset-specific disclosure requirements in IAS 16 Property, Plant and Equipment, IAS 38 Intangible Assets and IFRS 3 Business Combinations. In this section, we provide a brief overview of the impairment-related concepts and implementation issues for each of these standards. The objective of IAS 36 is to prescribe the procedures that an entity applies to ensure that its assets are carried at no more that their recoverable amount (IAS 36.1). Underlying the standard's prescriptions is a set of key definitions that include the following (lAS 36.6):

- Carrying amount: the amount at which an asset is recognized after deducting any accumulated depreciation (amortization) and accumulated impairment losses thereon.

- Cash-generating unit (CGU): the smallest identifiable group of assets that generates cash inflows that are largely independent of the cash inflows from other assets or groups of assets,

- Costs of disposal: incremental costs directly attributable to the disposal of an asset or CGU, excluding finance costs and income tax expense.

- Impairment loss: the amount by which the carrying amount of an asset or CGU exceeds recoverable amount.

- Fair value: the price that would be received to sell an asset or paid to transfer a liability in an orderly transaction between market participants at the measurement date.

- Recoverable amount the recoverable amount of en asset or a CGU is the higher of its fair value less costs of disposal aid its value in use.

- Value in use: the discounted present value of the future cash flows expected to be derived from an asset or CGU.

According to IAS 36, an entity is required to assess, at least at each reporting date, whether there is an indication that an asset may be impaired. If such indications are present, an impairment test should be undertaken. Although observing an indicator 
does not by itself lead to the recognition of a write-down, it is often considered as the trigger for conducting an impairment test.

To establish guidelines on identifying triggering events, the standard requires consideration of both external sources of information (e.g., unexpected decline in an asset's market value, increases in interest rates, or market capitalization being lower than the carrying amount of net assets) and internal sources of information (e.g., evidence on physical damage or obsolescence, discontinued or restructured operations, or a decline in economic performance) (lAS 36.12). If any such indication exists, the entity is required to estimate the recoverable amount of the asset which involves the use of judgment by management.

\section{Literature Review}

Impairment testing is an arena in which significant judgment is required, and current market conditions only increase the complexity involved. For indefinite-life intangibles, intangibles not yet available for use and for goodwill acquired in a business combination, the standard requires that an impairment test is carried out annually irrespective of whether or not any indication of impairment exists (IAS 36.10).

Recoverable amount is the higher of: (i) an asset's (or a CGU's) fair value less costs of disposal and its value in use (1AS 36.18). To measure impairment, an asset's (or a CGU's) carrying amount is compared with its recoverable amount. The impairment loss is the amount by which the carrying amount of the asset (or CGU) exceeds its recoverable amount (IAS 36.6, IAS 36.8).

Recoverable amount is determined for individual assets. If, however, the asset does not independently generate cash inflows, recoverable amount is determined for the cash-generating unit to which the asset belongs (1AS 36.22). The two elements in measuring recoverable amount are fair value less costs of disposal (FVLCD) and value in use (VIU). Lt may be possible to measure FVLCD, even if there is not a quoted price in an active market for an identical asset (IAS 36.20). However, in the absence of a basis for making a reliable estimate of the price at which an orderly transaction to sell the asset would take place between market participants, measuring FVLCD may not be possible. In this case, the entity may use the assets VIU as its recoverable amount (Ewert \& Wagenhofer, 2005).

Five elements should be reflected in an asset VIU (IAS 36, 30. The first two elements relate to net cash flow projections and require estimation of the amount and timing of expected future cash flows and changes in those projections. Cash flow projections should be bused on reasonable assumptions that represent management's best estimate of the range of economic conditions that will exist over the remaining useful life of the asset. These projections are usually produced on the busts of the most recent budgets/forecasts approved by management. Projections bend the period 
covered by the most recent budgets/forecasts should be based on extrapolations using a steady or declining growth rate, unless an increasing rate can be justified. If a growth rate is assumed, it should not exceed the tong-term average growth rate for the products, industries, or country or countries in which the entity operates, unless a higher rate can be justified (IAS 36.33).

The next three elements relate to the discount rate that is applied to the expected future cash flows. These are the time value of money, the price for bearing the assets inherent uncertainty and other factors that market participants reflect in pricing future cash flows. To measure the present value of projected cash flows, the focus is on capturing risks associated with the asset the riskier the asset, the higher the discount rate and the lower the present value $\&$ future cash flows. The standard requires the use of a pre-tax discount rate that reflects current market assessments of the time value of money as well as asset-specific risks (lAS 36.55). The selected discount rate should reflect investors required rate of return if they were to choose an investment that would generate similar cash flows (lAS 36.56).

However, in practice, it may not be possible to identify an asset-specific discount rate. In these circumstances, when a market-based rate is not directly observable, surrogates can be used by taking into account: (a) the entity's WACC using the Capital Asset Pricing Model; (b) the entity's incremental borrowing rate; (c) other market borrowing rates; and (d) key risk factors such as country risk, currency risk, price risk and cash flow risk (1AS 36.57 and AS 36. A16-A18).

\section{Recognition and Measurement of an Impairment Loss}

When the carrying amount of an asset exceeds its recoverable amount, the excess is recognized as an impairment loss (IAS 36.59). When the carrying amount is measured on the basis of depreciated historical cost, the impairment loss Is recognized as an expense immediately In profit or loss, If, however, the asset is measured under an accepted alternative basis (e.g., the revaluation model of IAS 16 or lAS 38), the impairment loss is treated as a reduction in the asset's revaluation surplus and recognized in other comprehensive income (1AS 36.60-61). The asset's revised impairment-adjusted carrying amount will be the basis for future periods' depreciation (amortization).

\section{Cash-generating Units and Goodwill Impairment}

In cases when it is not possible to estimate the recoverable amount of an individual asset, recoverable amount will be determined for the CGU to which the asset belongs (1AS 36.66). Identifying an asset's CGU can require judgment by management. The principal characteristic of a CGU is the ability of an asset (groups of assets) to independently generate cash inflows. In establishing this, various factors are 
considered, including how management monitors operations or how management makes decisions about continuing or disposing of assets and operations (1AS 36, 69).

An important aspect of identifying CGUs relates to goodwill accounting. Under FRS 3 Business Combinations, goodwill arising from business combinations is subject to annual impairment tests in accordance with lAS 36 (FRS 3. B69a). For purposes of impairment testing, acquired goodwill is, from the acquisition date , allocated to each of the acquirer's CGUs (or groups of CGUs) that are expected to benefit from the acquisition, irrespective of whether other acquired assets or liabilities are assigned to those CGUs.

The requirement to allocate goodwill, sterns from the fact that goodwill does not generate cash flows independently from other assets or groups of assets, and often contributes to the cash flows of multiple CGUs. But goodwill sometimes cannot be allocated on a non-arbitrary basis to individual CGUs. In such cases, goodwill is tested for impairment at the lowest level within the entity at which it is monitored for internal management purposes and which is not larger than an operating segment defined under IFRS 8 Operating Segments before aggregation (IAS 36.80-81).

ACGU to which goodwill has been allocated should be tested for impairment on an annual basis, and whenever there is an indication that the unit may be impaired. Impairment is tested by comparing the carrying amount of the CGU, including goodwill, with its recoverable amount. If the carrying amount of the CGU exceeds its recoverable amount, the entity should recognize the difference as an impairment loss (lAS 36, 90). Although the standard indicates that the annual impairment test for CGUs may be performed at any time during an annual period, to ensure consistency in entities' inter-period reporting practices, the test is to be performed at the same time every year (lAS 36.96). Any impairment loss is allocated first, to reduce the carrying amount of goodwill allocated to the CGU. If the carrying amount of goodwill allocated to the CGU is written off as a result of the loss, any remaining impairment is then allocated to the other assets of the CGU pro rats on the basis of their carrying amount (lAS 36.104). Figure 3.2 presents a summary overview of the impairment determination process for bath individual assets and cash-generating units based on IAS 36 .

\section{Selected Disclosure Requirements}

lAS 36 outlines required disclosures relating to impairment tests and recognized losses. We focus on a number of disclosure items in our compliance survey instrument. First, the standard requires the disclosure of the amount of impairment losses recognized in profit or loss and in other comprehensive income during the period (lAS 36.126 ). To identify how impairment losses relate to operating segments reported under IFRS 8 , the standard also requires the provision, for each reportable segment, of information at the amount of impairment losses recognized in profit or loss and in other 
comprehensive income during the period (IAS 36.129). 1AS 36 then lists a package of disclosures that should be provided for each material impairment loss recognized or reversed for an asset or a CGU (1AS 36.1 30). These include:

- The events that led to the recognition or reversal of the impairment loss

- The amount of the impairment loss recognized or reversed

- For an individual asset (i) the nature of the asset and (ii) the reportable segment to which the asset belongs

- For a cash-generating unit: (i) a description of the CGU, (ii) the amount of impairment toss recognized or reversed by class of assets and by reportable segment, and (iii) if the aggregation of assets for identifying the CGU has changed, a description of the current and former way of aggregation and the reasons for the change

- Whether the recoverable amount of the asset or CGU is its FVLCD or its VIU

- If recoverable amount is FVLCD, the basis used for its determination

- If recoverable amount is VIU, the discount rate(s) used in the current and previous estimates (if any)

It is possible that the initial allocation of acquired goodwill may not be complete by the end of the reporting period in which the business combination took place. In such situations, the entity must complete the initial allocation before the end 01 the first postacquisition reporting period (1AS 3684). For CGU disclosure purposes, If at the end of a reporting period, any portion of goodwill is not allocated to a OGU (group of CGUs), the amount of, and reasons for, unallocated goodwill should be disclosed (lAS 36133).

Further asset- and CGU-related impairment disclosures are outlined in IAS 36. For instance, entities are encouraged to disclose assumptions used to determine the recoverable amount during the period (IAS 36.132). More importantly, when the carrying amount of goodwill or intangible assets with indefinite useful lives allocated to a CGU (group of CGUs) is significant, 1AS 36 requires the provision of information on estimates used in determining the recoverable amount (IAS 36.134), including the following:

- The carrying amount of goodwill allocated to the CGU (group of CGUs)

- The carrying amount of intangible assets with indefinite useful lives allocated to the CGU (group of CGUs)

- The basis for the OGU's (group of CGUs') recoverable amount (i.e., VIU or FVLCD)

- If the CGU's (group of CGUs) recoverable amount is based on VIU: (i) a description of key assumptions relating to cash flow projections to which recoverable amount is most sensitive, (ii) a description of management's approach to determining values assigned to each key assumption, (iii) the 
projection period for future cash flows and reasons for why a period greater than five years may have been used, (iv) the growth rate used to extrapolate cash flow projections beyond the period covered by the most recent budgets or forecasts, and the justification for using a rate that exceeds the long-term average growth rate and (v) the discount rate(s) applied

- If the CGU's (group of CGUs) recoverable amount is based on FVLCD, the methodology used to determine FVLCD; if FVLGD is not determined using an observable quoted market price, the entity must disclose: (i) a description of each key assumption used in determining FVLCD to which recoverable amount is most sensitive, (ii) a description of management's approach to determining the values assigned to each key assumption: if FVLCD is determined using discounted cash flow projections, the entity must disclose: (iii) the period over which management has projected cash flows, (iv) the growth rate used to extrapolate cash flow projections and (v) the discount rate(s) applied to the cash flow projections

- If a reasonably possible change in a key assumption would cause a OGU's (group of CGU5') carrying amount to exceed recoverable amount (i) the amount by which the CGU's (group of GGUs) recoverable amount exceeds its carrying amount, (ii) the value assigned to the assumption and (iii) the amount by which the value assigned to the assumption must change for the CGIJ's (group of CGUs') recoverable amount to be equal to its carrying amount

If, on the other hand, some or the entire carrying amount of goodwill or indefinite-life intangible assets is allocated across multiple CGUs (groups of CGUs) and the amount so allocated is not significant this should also be disclosed. In addition, if the recoverable amounts of any of those CGUs (groups of CGU5) are based on the same key assumption(s) and the aggregate carrying amount of goodwill or indefinitelife intangible assets allocated to them is significant in comparison with the entity's total carrying amount of goodwill or intangible assets with indefinite useful lives, that fact should be disclosed together with the following information (IAS 36, 135):

- The aggregate carrying amount of goodwill allocated b those CGUs (groups of OGUs)

- The aggregate carrying amount of intangible assets with indefinite useful lives allocated to those CGUs (groups of CGUs)

- A description of the key assumptions

- A description of management's approach to determining the values assigned to the key assumptions (Leuz, 2010).

Since the primary objective of accounting is to provide information about the economic resources of an enterprise, the claims to those resources, and the effects of transactions, events, and circumstances that change the resources and claims; it is 
considered important to inform users of financial statement of any asset or cash generating unit that lose its capacity to recover its cost. This is necessary so as to provide accounting information users with relevant information about the change in value of the firm's resources (Akenbor, 2015).

An asset that loses its capacity to recover cost is said to be impaired. Loren, Brazley and Jefferson (2010) state that an impaired asset is a condition in which an asset's market value falls below its carrying amount and it is not expected to recover, it is a sudden or unexpected decline in an asset service utility. This means that an asset's market value is less than its book value and the future cash flows to be generated from the asset are less than the net difference between the market value and the book values, thereby resulting in impairment loss.

International Accounting Standards (lAS) 36 requires that assets be carried at no more than their recoverable amount; hence entities are required to test all assets that are within the scope of the standard (i.e. property, plant and equipment; and intangibles) for potential impairment when indicators of impairment exist or at least, annually for goodwill and intangible assets with indefinite useful lives. The controversies behind impairment testing necessitate a discussion regarding its overall costs and benefits. According to Reason (2003), implementing impairment testing on an annual basis for goodwill or when necessary for capital assets, can be very costly. Aside from the large monetary costs involved, impairment testing requires a great deal of time, effort and employee attention (Giannini, 2007).

When there is impairment loss, IAS (36) recommends that the value of the asset be written down in the books by debiting the impairment loss account and crediting the respective asset account since the asset cannot be carried at more than recoverable amount; and impairment loss be recognized as an expense in profit and loss account. Accounting for asset impairment provides financial statements users with relevant accounting information for rational decision making and it also serves as early signals of corporate collapse to management.

In spite of the controversies surrounding the cost and benefit of accounting for asset impairment, Lander (2004) noted that impairment charges, if applied correctly, provide investors and analysts with ways to assess company management and its decision-making track record. Managers that write down or write off assets due to impairment have not made first-class investment choices. He also noted that many business failures are preceded by a decline in the impairment value of assets. Such revelations could serve as early warning signals to the business stakeholders such as shareholders, management, creditors, employees, etc.

Accounting for asset impairment is faced with a few challenges. Meilu (2008) claimed that it can be difficult to determine which measure of value should be used when assessing impairment. Options include current cost (replacement cost), current 
market value (selling price), net realizable value (selling price minus disposal costs), or the sum of the future net cash flows from the income-generating unit. More so, there is little detailed guidance on accounting for asset impairments, when to recognize impairments, how impairments should be measured and how impairment should be disclosed.

Financial Accounting Standards (FAS) 121 required the use of both undiscounted future cash flows and fair values to recognize and measure impairment. Paragraph five of FAS 121 lists several impairment indicators, such as operating losses, significant adverse changes in the legal and economic climate and changes in the manner in which an asset is used. When one or more of these triggering el-nuts were present, an entity had to estimate the net future cash flows undiscounted and without interest charges associated with the use of that asset and its eventual disposition. When estimating cash flows, assets were grouped at the lowest level at which cash flows were identifiable and independent from other groups. If these cash flows were less than the carrying amount of the assets, the entity had to recognize an impairment loss. FAS 121, gains or losses on impairments of assets were reported in the income statement at ordinary income before income taxes, preferably under a separate caption. In addition, footnotes had to include $\mathrm{W}$ description of the impaired assets, the business segments in which the assets were located; the facts and circumstanc.es leading to impairment, the expected disposal date if applicable; and the carrying amount of these assets.

Prior to the issuance of FAS 142, certain triggering event had to occur before an impairment test is performed, as is mandated under FAS 121, which usually meant that an impairment test is never needed if the underlying transaction was profitable to the acquirer. Under FAS 142 this is o loner the case. Instead, intangible assets will be tested for impairment annually and on an interim basis if an event or circumstance occurs between annual tests that might reduce the air value of that asset. But under U.S. GAAP impaired assets must be recognized once there is evidence of a lack of recoverability of the net carrying amount. Once impairment has been recognized it cannot be restored.

According to Yio (2012), asset impairment occurs when there are: changes in regulation and business climate; declines in usage rate; technology changes; forecasts of a significant decline in the long-term, profitability of the asset. Gianini (2007) stated that once a company has determined that an asset is impaired, it can write down the asset or classify it an asset for sale. Assets will be written down if the company keeps on using the asset. Write-downs are sometimes included as part of a restructuring cost. It is important to be able to distinguish asset write-downs, which are non-cash expenses, from cash expenses like severance packages. Write- downs affect past reported income. The loss should be reported on the income statement before tax as a component of continuing operations. Generally impairment recognized for purposes until the affected 
assets are disposed of, that said, in most cases recognition of an impairment leads to a deferred tax asset (Hlousek, 2002).

Impaired assets held for sale are assets that are no longer in use and are expected to be disposed of or abandoned. The disposition decision differs from a writedown because once a company classifies impaired assets as assets for sale or abandonment it is actually severing these assets from assets of continuing operations as they are no longer expected to contribute to ongoing operations. This is the accounting impact: assets held for sales must be written down to fair value less the cost of selling them. These assets can no longer be depreciated (Yio, 2012).

As indicated by Loren et al (2010), and Yio(2012) the effect of assets impairment on financial statements and ratios of a firm is that the current income statement will include an impairment loss in income before tax from continuing operations.

\section{Empirical Evidence}

Timeliness, as one measure of financial reporting quality is relevant to the issue of impairment reporting. According to the 1ASB, timeliness means having information available to decision-makers in time to be capable of influencing their decisions ( Therefore, in the context of IFRS impairments for non-current non-financial assets, timeliness relates to the speed with which changes in the economic values of assets are recognized and any impairment losses are reflected in earnings (Giner and Rees, 2001).

Published research to date on impairments is generally limited to studies based on US data addressing managers' reporting incentives and reporting outcomes. Riecl (2004), for example, reports that SFAS 121 leads to higher associations between longlived asset write-offs and "big bath" reporting behavior. In this context, big bath reporting more likely reflects on managers' opportunistic behavior as opposed to the provision of private information about underlying performance. Beatty and Weber (2006) arrive at similar conclusions and find that both contracting and market incentives shape companies' impairment accounting choices. They show that equity market concerns affect companies' preferences for above-the-line versus below-theline accounting treatments, and that incentives related to debt contracting, management bonuses, executive turnover and exchange delisting effect firm's decisions to manage the timing of impairment recognition.

In a study of the outcomes of SFAS 142 impairments for goodwill and other intangible assets, Chen et al, (2008) use a returns-based model and find that, although the standard improves the timeliness of impairments, earnings still lag stock market returns in reflecting the effects of impairments. Bens et al. (2011) examine the information content of SFAS 142 goodwill impairments. They compare actual writeoffs and expected (model) write-offs and find a significant negative market reaction to 
the unexpected component of reported impairments, Lee (2011), on the other hand, reports on the favorable effects of SFAS 142 on the ability of goodwill to predict future cash flows. Contrary to earlier findings, Lee's study shows that the US standard does not lead to opportunistic abuse of reporting discretion and that it improves the representational faithfulness of goodwill numbers,

Impairment of non-current assets undoubtedly a challenging aspect of financial reporting and a source of potential loss of representational faithfulness. Impairment accounting requires assessments of future cash flows deriving from an asset and, as a result, judgments and estimates are of central importance. As Nobes (2011) notes, identifying the indicators that would lead to the recognition of impairments is essentially a matter of judgment. We cannot rule out the possibility that the degree of prudence exercised in judgments and estimates varies across companies and jurisdictions; for instance, due to historical tendencies toward more conservative or liberal accounting practices. Hence, there is potential for cross-country differences in the timing and amounts of impairment losses recognized under IAS 36.

We investigate the timeliness of bed news recognition and impairments in the post-2005 era using a test of the asymmetric timeliness of earnings (Basu, 1997; Pope and Walker, 1999; Ballet al., 2000; Raonic et al, 2004), This regression-based test estimates the extent to which economic gains and losses, measured based on positive and negative stock returns respectively, are reflected in accounting earnings. It captures the relative speeds of recognition of good news and bad news in earnings and in earnings components, Our emphasis is on examining differences in the speed of recognition of bad news across the three clusters of European countries based on the strength of their underlying institutions discussed earlier. We predict that companies in countries with stronger institutions will recognize bad news and impairments in a moretimely manner.

Proponents of IFRS contend that the IASB has taken steps to reduce the range of acceptable accounting treatments and to establish rules that better reflect economic position and financial performance. Limiting accounting alternatives can increase reporting quality by eliminating opportunities to manage earnings and balance sheet amounts. As Ewert and Wagenhofer (2005) and Barth et al. (2008) show, tightening accounting standards can result in earnings numbers that better reflect a firm's underlying economics. This, in turn, leads to information that can be more relevant to investors in decision-making.

A counter argument, however, suggests that for many countries, introduction of IFRS has involved a shift from a rules-based system to a principles-based system requiring frequent judgment and use of private information on the part of management (Jeanjean and Slolowy, 2008). Critics argue that the need to apply judgment and discretion presents managers with opportunities to pursue ulterior reporting motives by 
managing earnings (and other accounting amounts) in ways that reduce their information value to investors. Van, Tendeloo and Vanstraelen (2005) report evidence that is consistent with this prediction. They find that voluntary IFRS adopters in Germany have higher levels of earnings management than companies reporting under German accounting standards.

\section{Conclusion and Recommendations}

There is little doubt that the adequate implementation of IAS 36 can be a step toward reflecting the economic value of a firm's assets. But the standard has been criticized for being rooted in somewhat impractical requirements that call for subjective judgments and estimates that are unlikely to be verifiable. Unverifiable estimates can lead to inflated net assets, aggressively managed earnings and impairment decisions that essentially serve the purpose of managing earnings. Under such conditions, we would expect transparency to be low. Consistent with this view, a recent report by the ESMA expresses concern about the quality of disclosures on assumptions and judgments underlying impairments of non-financial assets (ESMA, 2011). Among the problem areas identified in the report are the lack of adequate justification for business plans and discount rates, absence of meaningful disclosures on impairment triggering events, excessive use of boilerplate language and the non-disclosure of information on assumptions used in determining recoverable amounts.

Evidence from IFRS reporting jurisdictions confirms implementation issues. For example, Petersen and Ptenborg (2010) report on inconsistencies in the implementation of IAS 36 especially in relation to how companies define a CGU and develop estimates for recoverable amounts. The discretion in selecting a discount rate can be used to opportunistically avoid or manage the timing of impairment losses, to the detriment of transparency, comparability and decision usefulness. Costs increase when companies are required to exercise discretion and to then make disclosures in support of their discretionary decisions. For example, if a standard were to specify a fixed discount rate to be used in valuing future cash flows (e.g., 10\%), this is less costly to a firm than being required to estimate an appropriate rate and justify the choice in the form of a disclosure note. Costs can arise in undertaking the analysis 10 support a decision, and in developing a justification and responding to questions and challenges from users.

Whenever management judgment is required in reporting decisions, such costs are potentially incurred. Amireshui et al (2011) describe such disclosure requirements as 'high effort'. They predict and test whether compliance is lower for relatively higheffort disclosures. They classify disclosure requirements into those that require high levels of effort and judgment (high-effort disclosures) and those for which compliance can be satisfied with minimum judgment or effort (low-effort disclosures). This latter group comprises those items for which companies can easily engage in using 
boilerplate language, as opposed to providing specific information that will assist users in better understanding the estimates and judgments underlying accounting measurements. Since assets impairment can distort the usefulness of accounting information for decision making, adequate attention should be made to ensure that the judgment and estimates made by managers are verified by auditing the estimates.

\section{References}

Akenbor, C.O. (2015). Accounting for assets impairment and corporate performance of Nigerian banks; Journal of Accounting Research; 1 (1); 5367.

Amiraslani, H., Latridis, G. E., \& Pope, P. F. (2013). Accounting for Asset Impairment: A test for IFRS Compliance in Europe. A Research Report by the centre for financial analysis and reporting research; Cass Business School.

ASB (1984). Recognition and measurement in financial statements of business enterprises. Concepts statement No. 5; Norwalk, CT.

Ball, R., Kothari, S. P. \& Robin, A. (2000). The effect of international institutional factors on properties of accounting earnings. Journal of Accounting and Economics. 29(1), pp. 1-51.

Barth, M. E., Landsman, W. R. \& Lang, M. H. (2008). International Accounting Standards and accounting quality. Journal of Accounting Research, 46(3); 467-498.

Basu, S. (1997). The conservatism principle and the asymmetric timeliness of earnings. Journal of Accounting and Economics, 24(1), pp. 3-37.

Beatty A. \& Weber J. (2006). Accounting discretion in fair value estimates: An examination of SFAS 142 goodwill impairments. Journal of Accounting Research; 44(2); 257-288.

Bens, D. A., Heltzer, W. \& Segal, B. (2011). The information content of goodwill impairments and SFAS 142. Journal of Accounting, Auditing and Finance, 26(3); 527-555.

Carlin, T. M. \& Finch, N. (2009). Discount rates in disarray: Evidence on flawed goodwill impairment testing. Australian Accounting Review, 19(4), pp. 326336.

Chen, C., Kohlbeck, M. \& Warfield, T. (2008). Timeliness of impairment recognition: Evidence from the initial adoption of SFAS 142. Advances in Accounting, 24(1); 72-81. 
Ewert, R. \& Wagenhofer, A. (2005). Economic effects of tightening accounting standards to restrict earnings management. The Accounting Review, 80(4); 1101-1124.

FASB (1980). Qualitative characteristics of accounting information: Concepts statement No. 2; Norwalk, CT.

Giannini, E. (2007). Impairment of assets or impairment of financial information. The Honors Program. Senior Capstone Project.

Hlousek, R. (2002). Asset impairment: transitioning under FAS 142. Retrieved on 18th March 2011 from http://www.cogentvaluation.com;

Lee, C. (2011). The effect of SFAS 142 on the ability of goodwill to predict future cash flows. Journal of Accounting and Public Policy, 30(3), pp. 236-255.

Leuz, C. (2010). Different approaches to corporate reporting regulation: How jurisdictions differ and why. Accounting and Business Research, 40(3), pp. 229-256.

Giner, B. \& Rees, W. (2001). On the asymmetric recognition of good and bad news in France, Germany and the United Kingdom. Journal of Business Finance and Accounting, 28(9-10); 1285-1331.

Jeanjean, T. \& Stolowy, H. (2008). Do accounting standards matter? An exploratory analysis of earnings management before and after IFRS adoption, Journal of Accounting and Public Policy, 27(6), pp. 480-494.

Loren, A. N., Bazley, J. A., \& Jefferson, P. J. (2010). Intermediate Accounting. Australia: South-Western/Cengage Learning.

Meilu, R. (2008). Accounting for the impairment of capital assets. International Journal of Auditing and Assurance Services; 4(1), 93-105

Nobes, C. W. (2011). IFRS practices and the persistence of accounting system classification. Abacus, 47(3), pp. 267-283.

Petersen, C. \& Plenborg, T. (2010). How do firms implement impairment tests of goodwill? Abacus, 46(4), pp. 419-446.

Pope, P. F. \& Walker, M. (1999). International differences in the timeliness, conservatism and classification of earnings. Journal of Accounting Research, 37(Supplement), pp. 53-87. 
Raonic, I., McLeay, S. J. \& Asimakopoulos, I. (2004). The timeliness of income recognition by European companies: An analysis of institutional and market complexity. Journal of Business Finance and Accounting, 31(1-2), pp. 115148.

Reason, T. (2003). Accounting for the impairment of long-lived and intangible assets. Managerial accounting Journal; 7(2), 166-193

Riedl, E. J. (2004). An examination of long-lived asset impairments. The Accounting Review; 79(3), pp. 823-852.

VanTendeloo, B. \& Vanstraelen, A. (2005). Earnings management under German GAAP versus IFRS. European Accounting Review, 14(1); 155-180.

Watts, R. L. (2003). Explanation and implications. Accounting Horizons; 17(1), 207210.

Yio, K. I. (2012). Asset impairment: Effects on financial statements. Global Accounting Research Review; 12(3), 41-49 